\title{
Early Endoscopy Can Shorten the Duration of Hospitalization in Suspected Variceal Hemorrhage
}

\author{
Hong-Lin Guan, ${ }^{1}$ Hsin-Yi Lin, ${ }^{1}$ Yi-Kung Lee, ${ }^{1,2}$ Chen-Yang Hsu, ${ }^{3}$ and Yung-Cheng Su ${ }^{1,2}$ \\ ${ }^{1}$ Emergency Department, Dalin Tzu Chi Hospital, Buddhist Tzu Chi Medical Foundation, Chiayi County 622, Taiwan \\ ${ }^{2}$ School of Medicine, Tzu Chi University, Hualien 970, Taiwan \\ ${ }^{3}$ Department of Public Heath, National Taiwan University, Taipei 106, Taiwan
}

Correspondence should be addressed to Yung-Cheng Su; drsul19@gmail.com

Received 16 June 2013; Accepted 5 July 2013

Academic Editors: S. M. Abbas and R. Cirocchi

Copyright (C) 2013 Hong-Lin Guan et al. This is an open access article distributed under the Creative Commons Attribution License, which permits unrestricted use, distribution, and reproduction in any medium, provided the original work is properly cited.

\begin{abstract}
Background. Endoscopic treatment in patients with acute variceal hemorrhage should be performed within 12 hours, but the recommendation is based on the experts' opinion. Objective. Our study investigated if time to endoscopy was a significant factor that could alter the outcomes of patients with suspected variceal hemorrhage. The primary outcome was the length of hospital stay and the mortality. The secondary outcomes were complications during observation periods. Methods. Patients were included if variceal hemorrhage was suspected in the emergency department. Patients were further divided into early (receiving endoscopy within 12 hours) and delayed groups (receiving endoscopy after 12 hours), and each patient was matched using a standard propensity score greedy-matching algorithm. The primary and secondary outcomes were compared accordingly. Results. 1442 patients met our inclusion criteria and therefore were enrolled for further analysis. In the Cox regression model, log time to endoscopy was not a significant factor. In the propensity score assignment, 566 patients (283 in each group) were further selected into the subcohort $(P$ value $=0.8001)$. Kaplan-Meier curves showed a discharge benefit favoring the early endoscopy over the control group. The mortality rates and complications were not statistically different between the two groups $(P$ value $=0.0045)$. Conclusion. Early endoscopy before 12 hours in patients with suspected variceal hemorrhage could result in shorter length of hospitalization without increasing the mortalities and complications. The results would help emergency physicians in decisions making when these patients are encountered.
\end{abstract}

\section{Introduction}

Acute variceal hemorrhage is a life-threatening complication of liver cirrhosis $[1,2]$. Unlike nonvariceal bleeding, only 50 percent of patients with variceal hemorrhage stop spontaneously, and time management is necessary in order to improve the outcome. In addition to medical therapy, endoscopic treatment is considered currently the definitive treatment of choice [3]. Theoretically, early endoscopy can achieve quicker hemostasis, prevent possible complications, and decrease transfusions and length of hospital stay [4-6]. However, the insufficient preparation time may also lead to some drawbacks such as incomplete examination and aspiration. In the guideline published by the American Association for the Study of Liver Diseases and the American College of Gastroenterology [7], endoscopic treatment should be performed within 12 hours, but the recommendation is based on the experts' opinion [8].

Several studies based on the timing of endoscopy in variceal bleeding were controversial [8-11]. The results were limited on the relative small case numbers, and the length of hospital stay was not taken into account. Our study retrospectively compared patients receiving endoscopy for suspected variceal hemorrhage to examine if the time to endoscopy can alter the outcomes in this cohort. The primary objective was to compare the duration of hospital stay between the two groups. The secondary outcomes were complications (resuscitations, repeated endoscopy, urgent operations, 14 day rebleeding, and 30-day all causes mortalities after discharge) during observation periods. 


\section{Methods}

2.1. Study Setting. The study was a retrospective observational study. Buddhist Tzu Chi Dalin General Hospital is a teaching hospital located in the area where the prevalence of liver cirrhosis is highest among the country. Attending physicians of gastrologists on duty performed all endoscopies. On average, we received ten to twelve episodes of suspected variceal hemorrhage every month. Medical records for patients with suspected variceal hemorrhage in the ED between January 2001 and September 2011 were reviewed, and data were extracted by two authors (S. Y. C. and L. Y. K.). The analysis was performed by another author (H. C. Y.) after the completion of the data collection. The study was approved by the institutional review boards (IRB) of Buddhist Tzu Chi Dalin General Hospital.

2.2. Patients. Patients were considered for inclusion if they were suspected cirrhotic and received terlipressin (the only medication for variceal hemorrhage in our hospital) in the ED because of gastrointestinal bleeding (GIB). They were excluded if endoscopy was not performed, the indication of terlipressin was not for GIB, or prolonged hospitalization because of reasons other than GIB. We defined early endoscopy when the procedure was performed within 12 hours on arrival to the ED [7]. We searched our electronic medical records during the study period to identify our study cohort. Age, sex, duration of hospital stay, antibiotic use in the ED, time to endoscopy, endoscopists, endoscopic findings, endoscopic treatments, treating physicians, and laboratory results were directly retrieved from computerized records. We further reviewed all the medical charts to gather the detailed information such as comorbidities, death and complications. For patients who were discharged from our hospital, a follow-up period of minimal 30 days was traced to check if there was mortality from any cause or readmission because of GIB during this period. All patients with suspected variceal hemorrhage were monitored with respiratory rate, pulse oximeter, electrocardiography, and blood pressure in the $\mathrm{ED}$, and terlipressin was routinely administered before the endoscopy. Antibiotics before endoscopy were administered based on the decisions of individual emergency physicians.

2.3. Statistical Analysis. Continuous variables were compared with $t$-test and categorical variables with $\chi^{2}$ test. 95\% confidence interval (CI) and $P$ value were reported. A $P$ value of less than 0.05 was considered significant. All analyses were performed using Statistical Analysis Software for Windows, version V.9.2 (SAS Institute Inc., Cary, NC) and STATA version 11.2 (StataCorp, College Station, TX, USA).

2.4. Regression Models. We used a multivariate Cox regression model to identify if time to endoscopy was associated with survival events in the cohort. A patient discharged alive from the hospital was regarded as censored (nonevent) on the time of discharge. The duration of hospital stay was defined as the duration from ED arrival to discharge from hospital. Age, sex, initial symptoms (bloody stool,

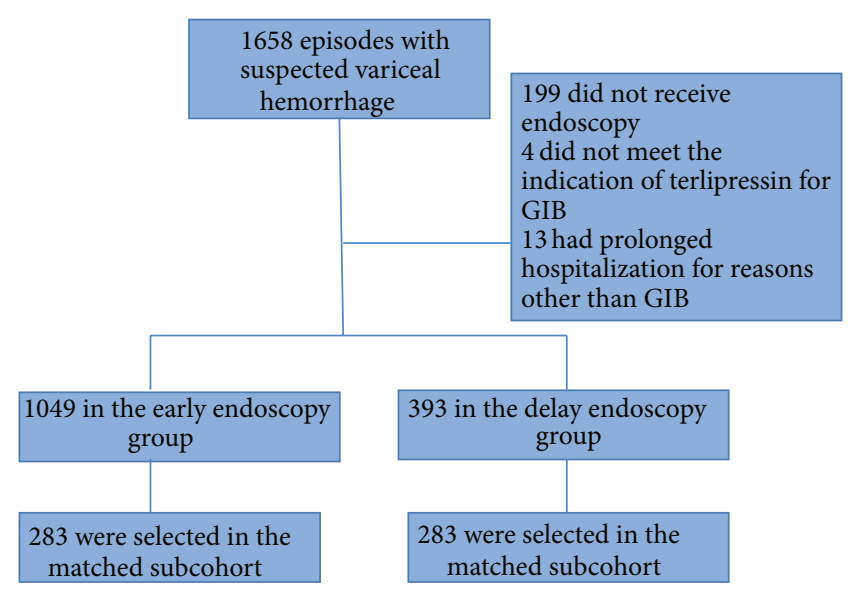

FIGURE 1: Selection process of patients.

melena, coffee ground emesis, hematemesis), initial vital signs (heart rates, blood pressure, respiratory rates and body temperature), log time to endoscopy, child criteria of liver cirrhosis, endoscopists, treating physicians, antibiotics use at ED, laboratory results (hemoglobin, white blood cell counts, platelet counts, partial thromboplastin time (PTT), sodium, potassium, glucose, blood urea nitrogen (BUN), creatinine, and aspartate aminotransferase (AST)), and comorbidities (alcoholism, hepatitis B or C carrier, and malignancies) were added to the multivariate model to find out the possible predictors for survival events.

2.5. Propensity Score Methods. The propensity score was the conditional probability for early endoscopy under possible confounders. Age, sex, initial symptoms, initial vital signs, child criteria of liver cirrhosis, endoscopists, treating physicians, antibiotics use, laboratory results, and comorbidities were added into a multivariable logistic regression model to predict the effect of early endoscopy [12]. The predicted probability from the model was used as the propensity score for each patient. We then matched each patient in the early endoscopy group to the patient in the control group with the closest propensity score, using a standard greedymatching algorithm $[13,14]$. After the 1:1 matched groups were assembled, the primary and secondary outcomes were compared accordingly. Kaplan-Meier curves were plotted to show the trend. Log-rank test was used to compare the difference of hospital stay and mortality between the early endoscopy and control groups.

\section{Results}

By reviewing of medical records, we identified 1658 episodes of suspected variceal hemorrhage in the ED during the 11year study period. 1442 patients met our inclusion criteria and therefore were enrolled for further analysis. The selection process was summarized in Figure 1. The baseline characteristics are shown in Table 1. Before adjustment for possible confounding variables, the average duration of hospital stay was 7.74 days (95\%CI, 0.09-65.53) in the early endoscopy 
TABLE 1: Baseline characteristics of patients in the early and delayed endoscopy groups (suspected variceal hemorrhage).

\begin{tabular}{|c|c|c|c|c|}
\hline & All patients $(N=1442)$ & Early endoscopy $(N=1049)$ & Delayed endoscopy $(N=393)$ & $P$ value \\
\hline Men & $1135(37.7 \%)$ & $814(77.6 \%)$ & $321(81.7 \%)$ & 0.0918 \\
\hline Age (year) & $57.0(13.3)$ & $57.1(13.4)$ & $56.6(13.0)$ & 0.4887 \\
\hline \multicolumn{5}{|l|}{ Initial symptoms } \\
\hline Red blood emesis & $707(49.03 \%)$ & $540(51.48 \%)$ & $167(42.49 \%)$ & \multirow{5}{*}{0.0034} \\
\hline Coffee grounds & $177(12.27 \%)$ & $126(12.01 \%)$ & $51(12.98 \%)$ & \\
\hline Hematochezia & $33(2.29 \%)$ & $20(1.91 \%)$ & $13(3.31 \%)$ & \\
\hline Melena & $453(31.41 \%)$ & $321(30.60 \%)$ & $132(33.59 \%)$ & \\
\hline Others & $72(4.99 \%)$ & $42(4.00 \%)$ & $30(7.63 \%)$ & \\
\hline Mean arterial pressure $(\mathrm{mmHg})$ & $87.0(19.9)$ & $86.5(20.1)$ & $88.5(19.2)$ & 0.0724 \\
\hline Heart rates (beats/min) & $103.7(21.8)$ & $104.3(22.1)$ & $102.1(21.0)$ & 0.0790 \\
\hline Respiratory rates (/minutes) & $17.2(3.1)$ & $17.4(3.0)$ & $16.8(3.2)$ & 0.0027 \\
\hline Body temperature $\left({ }^{\circ} \mathrm{C}\right)$ & $36.6(0.8)$ & $36.5(0.8)$ & $36.7(0.9)$ & 0.0022 \\
\hline \multicolumn{5}{|l|}{ Child's classification } \\
\hline A & $408(28.29 \%)$ & $301(28.69 \%)$ & $107(27.23 \%)$ & \multirow{3}{*}{0.0732} \\
\hline $\mathrm{B}$ & $659(45.70 \%)$ & $492(46.90 \%)$ & $167(42.49 \%)$ & \\
\hline $\mathrm{C}$ & $375(26.01 \%)$ & $256(24.40 \%)$ & $119(30.28 \%)$ & \\
\hline Time to endoscopy (hour) & $9.1(10.7)$ & $4.6(2.9)$ & $20.9(14.2)$ & $<0.0001$ \\
\hline \multicolumn{5}{|l|}{ Antibiotics use at ED } \\
\hline Yes & $138(9.57 \%)$ & $89(8.48 \%)$ & $49(12.7 \%)$ & \multirow{2}{*}{0.0220} \\
\hline No & $1304(90.49 \%)$ & $960(91.52 \%)$ & $344(87.53 \%)$ & \\
\hline Hemoglobin (g/dL) & $9.2(2.4)$ & $9.2(2.5)$ & $9.3(2.4)$ & 0.3914 \\
\hline White blood cells counts $\left(10^{3} / \mathrm{uL}\right)$ & $9.68(6.6)$ & $9.89(7.1)$ & $9.13(4.9)$ & 0.0226 \\
\hline Platelet counts $\left(10^{3} / \mathrm{uL}\right)$ & $127(82.3)$ & $127(80.2)$ & $127(87.5)$ & 0.9998 \\
\hline PTT (seconds) & $30.8(8.8)$ & $30.7(8.9)$ & $31.1(8.5)$ & 0.5080 \\
\hline Sodium (mmol/L) & $134.9(5.4)$ & $135.2(5.3)$ & $134.1(5.6)$ & 0.0007 \\
\hline Potassium (mmol/L) & $4.2(0.76)$ & $4.2(0.75)$ & $4.1(0.80)$ & 0.1071 \\
\hline BUN (mg/dL) & $32(21.3)$ & $33(21.4)$ & $31(20.9)$ & 0.2806 \\
\hline Creatinine (mg/dL) & $1.4(1.3)$ & $1.4(1.4)$ & $1.4(1.2)$ & 0.9169 \\
\hline Glucose (mg/dL) & $173(100.1)$ & $171(92.3)$ & $178(118.4)$ & 0.3423 \\
\hline AST (IU/L) & $104(180.8)$ & $103(163.1)$ & $106(221.4)$ & 0.7930 \\
\hline \multicolumn{5}{|l|}{ Causes of cirrhosis } \\
\hline Hepatitis B & $327(22.68 \%)$ & $247(23.55 \%)$ & $80(20.36 \%)$ & 0.1977 \\
\hline Hepatitis C & $462(32.04 \%)$ & $340(32.41 \%)$ & $122(31.04 \%)$ & 0.6200 \\
\hline Alcoholism & $570(39.53 \%)$ & $408(38.89 \%)$ & $162(41.22 \%)$ & 0.4209 \\
\hline \multicolumn{5}{|l|}{ Malignancies } \\
\hline Yes & $442(30.65 \%)$ & $315(30.03 \%)$ & $127(32.32 \%)$ & \\
\hline No & $1000(69.35 \%)$ & $734(69.97 \%)$ & $266(67.68 \%)$ & 0.4016 \\
\hline \multicolumn{5}{|l|}{ Proved variceal hemorrhage } \\
\hline Yes & $949(65.81 \%)$ & $728(69.40 \%)$ & $221(56.23 \%)$ & \multirow{2}{*}{$<0.0001$} \\
\hline No & $493(34.19 \%)$ & $321(30.60 \%)$ & $172(43.77 \%)$ & \\
\hline \multicolumn{5}{|l|}{ Endoscopic treatment } \\
\hline None & $473(32.80 \%)$ & $302(28.79 \%)$ & $171(43.51 \%)$ & \multirow{5}{*}{$<0.0001$} \\
\hline Band ligation & $655(45.42 \%)$ & $498(47.47 \%)$ & $157(39.95 \%)$ & \\
\hline Sclerotherapy & $181(12.55 \%)$ & $141(13.44 \%)$ & $40(10.18 \%)$ & \\
\hline Combined & $18(1.25 \%)$ & $14(1.33 \%)$ & $4(1.02 \%)$ & \\
\hline Ulcer related & $115(7.98 \%)$ & $94(8.96 \%)$ & $21(5.34 \%)$ & \\
\hline \multicolumn{5}{|l|}{ Death } \\
\hline Yes & $157(10.89 \%)$ & $120(11.44 \%)$ & $37(9.41 \%)$ & \multirow{2}{*}{0.2717} \\
\hline No & $1285(89.11 \%)$ & $929(88.56 \%)$ & $356(90.59 \%)$ & \\
\hline Duration of hospital stay (day) & $7.97(7.5)$ & $7.74(7.2)$ & $8.59(8.1)$ & 0.0551 \\
\hline
\end{tabular}


TABle 1: Continued.

\begin{tabular}{|c|c|c|c|c|}
\hline & All patients $(N=1442)$ & Early endoscopy $(N=1049)$ & Delayed endoscopy $(N=393)$ & $P$ value \\
\hline \multicolumn{5}{|l|}{ Complications } \\
\hline All & $326(22.61 \%)$ & $243(23.16 \%)$ & $83(21.12 \%)$ & 0.4084 \\
\hline Repeated endoscopy & $192(13.31 \%)$ & $145(13.82 \%)$ & $47(11.96 \%)$ & 0.3537 \\
\hline Operations & $42(2.91 \%)$ & $32(3.05 \%)$ & $10(2.54 \%)$ & 0.6109 \\
\hline Balloon tamponade & $21(1.46 \%)$ & $18(1.72 \%)$ & $3(0.76 \%)$ & 0.1788 \\
\hline 14-day rebleeding & $102(7.07 \%)$ & $77(7.34 \%)$ & $25(6.36 \%)$ & 0.5185 \\
\hline 30-day all cause mortalities & $35(2.43 \%)$ & $25(2.39 \%)$ & $10(2.54 \%)$ & 0.8614 \\
\hline
\end{tabular}

Continuous variables were displayed as mean and standard deviation (SD); categorical variables were displayed as numbers and percentage.

group and 8.59 days (95\%CI, $0.57-81.54$ ) in the control group, respectively. The mortality rates were similar between the two groups $(11.44 \%$ versus $9.41 \%, P$ value $=0.2717)$ and so the all causes of complications $(23.16 \%$ versus $21.12 \%, P$ value $=0.4084$ ) (Table 1 ). After adjusting for above-mentioned covariates, log time to endoscopy was not shown to be a significant factor of survival events in the multivariate Cox regression model (hazard ratio $=0.974 ; P$ value $=0.8001$ ) .

In the propensity score assignment, the covariates mentioned above were added into the multivariate logistic model to predict the effect of early endoscopy. The propensity score-matching process selected 283 patients from the early endoscopy group and the other 283 from the control group for further analysis (Figure 1). Baseline characteristics were similar in the two groups (Table 2). In the propensity score matched subcohort, the early endoscopy group was again found to be associated with shorter hospital stay compared with control group (7.39 days versus 8.46 days, $P$ value $(\log$-rank test $)=0.0045)$ when mortalities were taken into account. Kaplan-Meier curves showed a discharge benefit favoring the early endoscopy over the control group. (Figure 2) The mortality rates and complications were not statistically different between the two groups.

\section{Discussion}

Improvements in medical therapy have changed the prognosis of the patients with variceal hemorrhage [15]. However, the optimal "time to endoscopy" has not been defined to date. In the advance of vasoactive medications [16, 17], it has been argued whether the early endoscopy could alter the outcome. Hsu et al. [10, 11] found that delayed endoscopy of more than 15 hours could increase the mortality, but the sensitivity and specificity are relatively low (72.0\% and 59.4\%, resp.), and the results could not be generalized to patients with uninvestigated GIB. We focused our study interest on patients with suspected variceal hemorrhage because the results could be more relevant to the decision making of emergency physicians. To our knowledge, this study is the first one that proved that early endoscopy of less than 12 hours could result in shorter hospital stay in patients with suspected variceal hemorrhage without increasing the mortalities or the complications. The effects not only can save the use of monitoring beds but also decrease the costs of hospitalization.

While increasing the strength of the recommendation of current guidelines $[7,8,18]$, we also found that the treatment

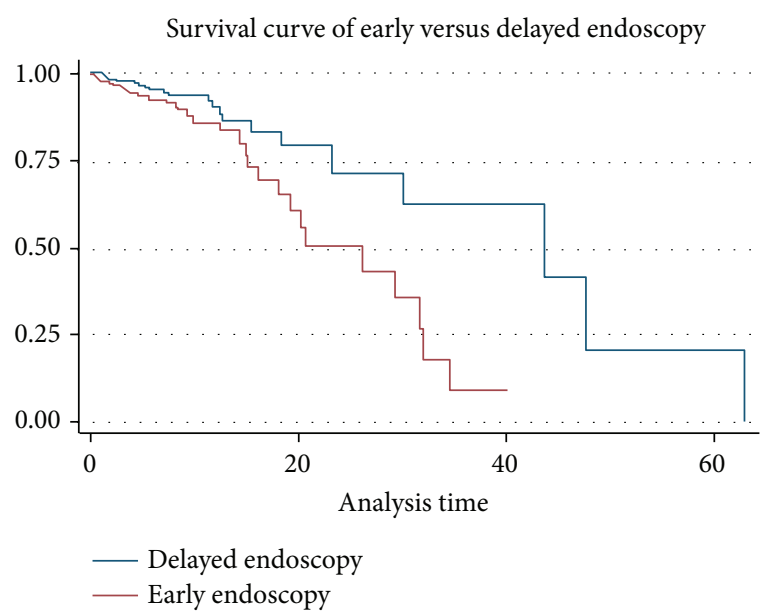

FIGURE 2: Survival curves of early and delayed endoscopy group.

benefits of endoscopy were not positively correlated with shorter duration based on the results of multivariate Cox regression model. During the first few hours, the endoscopic treatment may be suboptimal because of the poor preparation, and benefits of medical therapy (e.g., vasoactive agents, fluid resuscitation, etc.) may outweigh the earlier endoscopy [10]. To avoid the problems of multiple comparisons, we did not repeat our statistical tests by redefining the cut-off time. As a result, the best door-to-scope time cannot be determined in our study.

We had to acknowledge some study limitations. Our study was conducted in the retrospective fashion, and as a result, the unmeasured confounding and missing data would be argued. Most of our core variables were retrieved from the computerized records, and missing data were not an issue. Although prospective randomized controlled trials would ideally eliminate the unmeasured confounding, such study designs were difficult for ethical concerns. To overcome this limitation, we enrolled a relative large number of cases compared with other studies [8-11] and adjusted the possible covariates extensively. After the adjustment, the discharge benefit in the early endoscopy group is significant enough that we did not think that there were other possible factors that could fully explain the effect.

In conclusion, early endoscopy before 12 hours in patients with suspected variceal hemorrhage could result in shorter 
TABLE 2: Baseline characteristics of patients in the early and delayed endoscopy groups (propensity score matched subcohort).

\begin{tabular}{|c|c|c|c|}
\hline & Early endoscopy $(N=283)$ & Delayed endoscopy $(N=283)$ & $P$ value \\
\hline Men & $221(78.09 \%)$ & $227(80.21 \%)$ & 0.5347 \\
\hline Age (year) & $57.9(12.0)$ & $57.7(13.5)$ & 0.8928 \\
\hline \multicolumn{4}{|l|}{ Initial symptoms } \\
\hline Red blood emesis & $128(45.23 \%)$ & $135(47.70 \%)$ & \multirow{5}{*}{0.6401} \\
\hline Coffee grounds & $30(10.60 \%)$ & $37(13.07 \%)$ & \\
\hline Hematochezia & $9(3.18 \%)$ & $5(1.77 \%)$ & \\
\hline Melena & $97(34.28 \%)$ & $88(31.10 \%)$ & \\
\hline Others & $19(6.71 \%)$ & $18(6.36 \%)$ & \\
\hline Mean arterial pressure $(\mathrm{mmHg})$ & $86.4(19.5)$ & $88.7(18.3)$ & 0.1522 \\
\hline Heart rates (beats/min) & $102.5(20.6)$ & $102.1(21.0)$ & 0.8447 \\
\hline Respiratory rates (/minutes) & $17.3(3.1)$ & $16.8(3.2)$ & 0.0759 \\
\hline Body temperature $\left({ }^{\circ} \mathrm{C}\right)$ & $36.6(0.8)$ & $36.6(0.8)$ & 0.4955 \\
\hline \multicolumn{4}{|l|}{ Child's classification } \\
\hline A & $77(27.21 \%)$ & $80(28.27 \%)$ & \multirow{3}{*}{0.9610} \\
\hline $\mathrm{B}$ & $126(44.52 \%)$ & $124(43.82 \%)$ & \\
\hline $\mathrm{C}$ & $80(28.27 \%)$ & $79(27.92 \%)$ & \\
\hline Time to endoscopy (hour) & $4.7(3.0)$ & $20.8(15.5)$ & $<0.0001$ \\
\hline \multicolumn{4}{|l|}{ Antibiotics use at ED } \\
\hline Yes & $32(11.31 \%)$ & $30(10.60 \%)$ & \multirow{2}{*}{0.7878} \\
\hline No & $251(88.69 \%)$ & $253(89.40 \%)$ & \\
\hline Hemoglobin (g/dL) & $9.3(2.6)$ & $9.4(2.5)$ & 0.6234 \\
\hline White blood cells counts $\left(10^{3} / \mathrm{uL}\right)$ & $9.15(5.5)$ & $9.35(5.2)$ & 0.6508 \\
\hline Platelet counts $\left(10^{3} / \mathrm{uL}\right)$ & $124(85.5)$ & $126(91.2)$ & 0.8100 \\
\hline PTT (seconds) & $31.0(9.1)$ & $30.8(7.5)$ & 0.7593 \\
\hline Sodium (mmol/L) & $134.9(5.4)$ & $134.6(5.3)$ & 0.5340 \\
\hline Potassium $(\mathrm{mmol} / \mathrm{L})$ & $4.2(0.79)$ & $4.1(0.71)$ & 0.2740 \\
\hline BUN (mg/dL) & $31(19.4)$ & $33(20.9)$ & 0.2173 \\
\hline Creatinine (mg/dL) & $1.3(1.1)$ & $1.4(1.1)$ & 0.6498 \\
\hline Glucose (mg/dL) & $169(93.6)$ & $173(112.2)$ & 0.6442 \\
\hline AST (IU/L) & $109(172.2)$ & $108(238.7)$ & 0.9456 \\
\hline \multicolumn{4}{|l|}{ Causes of cirrhosis } \\
\hline Hepatitis B & $61(21.55 \%)$ & $61(21.55 \%)$ & 1.000 \\
\hline Hepatitis C & $101(35.69 \%)$ & $89(31.45 \%)$ & 0.2855 \\
\hline Alcoholism & $107(37.81 \%)$ & $106(37.46 \%)$ & 0.9309 \\
\hline \multicolumn{4}{|l|}{ Malignancies } \\
\hline Yes & $91(32.16 \%)$ & $86(30.39 \%)$ & \multirow{2}{*}{0.6503} \\
\hline No & $192(67.84 \%)$ & $197(69.61 \%)$ & \\
\hline \multicolumn{4}{|l|}{ Proved variceal hemorrhage } \\
\hline Yes & $197(69.61 \%)$ & $156(55.12 \%)$ & \multirow{2}{*}{0.0004} \\
\hline No & $86(30.39 \%)$ & $127(44.88 \%)$ & \\
\hline \multicolumn{4}{|l|}{ Endoscopic treatment } \\
\hline None & $91(32.16 \%)$ & $126(44.52 \%)$ & \multirow{5}{*}{0.0231} \\
\hline Band ligation & $143(50.53 \%)$ & $109(38.52 \%)$ & \\
\hline Sclerotherapy & $30(10.60 \%)$ & $28(9.89 \%)$ & \\
\hline Combined & $1(0.35 \%)$ & $3(1.06 \%)$ & \\
\hline Ulcer related & $18(6.36 \%)$ & $17(6.01 \%)$ & \\
\hline \multicolumn{4}{|l|}{ Death } \\
\hline Yes & $37(13.07 \%)$ & $24(8.48 \%)$ & \multirow{2}{*}{0.0780} \\
\hline No & $246(86.93 \%)$ & $259(91.52 \%)$ & \\
\hline Duration of hospital stay (day) & $7.39(5.7)$ & $8.46(7.4)$ & 0.0544 \\
\hline
\end{tabular}


TABLE 2: Continued.

\begin{tabular}{lccc}
\hline & Early endoscopy $(N=283)$ & Delayed endoscopy $(N=283)$ & $P$ value \\
\hline Complications & & & \\
All & $67(23.67 \%)$ & $60(21.20 \%)$ & 0.4806 \\
Repeated endoscopy & $48(16.96 \%)$ & $38(13.43 \%)$ & 0.2416 \\
Operations & $3(1.06 \%)$ & $7(2.47 \%)$ & 0.2019 \\
Balloon tamponade & $7(2.47 \%)$ & $2(0.71 \%)$ & 0.0929 \\
14-day rebleeding & $17(6.01 \%)$ & $16(5.65 \%)$ & 0.8576 \\
30-day all cause mortalities & $8(2.83 \%)$ & $8(2.83 \%)$ & 1.0000 \\
\hline
\end{tabular}

Continuous variables were displayed as mean and standard deviation (SD); categorical variables were displayed as numbers and percentage.

length of hospitalization without increasing the mortalities and complications. However, the discharge benefits are not positively correlated with shorter duration. The results would help emergency physicians in decisions making when these patients are encountered.

\section{Conflict of Interests}

The authors declare that they have no conflict of interests.

\section{References}

[1] D. Prandi, B. Rueff, and J. Roche Sicot, "Life threatening hemorrhage of the digestive tract in cirrhotic patients. An assessment of the postoperative mortality after emergency portacaval shunt," American Journal of Surgery, vol. 131, no. 2, pp. 204-209, 1976.

[2] R. Jutabha and D. M. Jensen, "Management of upper gastrointestinal bleeding in the patient with chronic liver disease," Medical Clinics of North America, vol. 80, no. 5, pp. 1035-1068, 1996.

[3] N. D. Grace, "Diagnosis and treatment of gastrointestinal bleeding secondary to portal hypertension. American College of Gastroenterology Practice Parameters Committee," American Journal of Gastroenterology, vol. 92, no. 7, pp. 1081-1091, 1997.

[4] G. S. Cooper, A. Chak, L. E. Way, P. J. Hammar, D. L. Harper, and G. E. Rosenthal, "Early endoscopy in upper gastrointestinal hemorrhage: associations with recurrent bleeding, surgery, and length of hospital stay," Gastrointestinal Endoscopy, vol. 49, no. 2, pp. 145-152, 1999.

[5] B. M. R. Spiegel, N. B. Vakil, and J. J. Ofman, "Endoscopy for acute nonvariceal upper gastrointestinal tract hemorrhage: is sooner better? A systematic review," Archives of Internal Medicine, vol. 161, no. 11, pp. 1393-1404, 2001.

[6] A. Barkun, M. Bardou, and J. K. Marshall, "Consensus recommendations for managing patients with nonvariceal upper gastrointestinal bleeding," Annals of Internal Medicine, vol. 139, no. 10, pp. 843-857, 2003.

[7] G. Garcia-Tsao, A. J. Sanyal, N. D. Grace, and W. Carey, "Prevention and management of gastroesophageal varices and variceal hemorrhage in cirrhosis," Hepatology, vol. 46, no. 3, pp. 922-938, 2007.

[8] Y. Hsu, C.-S. Chung, and H.-P. Wang, "Application of endoscopy in improving survival of cirrhotic patients with acute variceal hemorrhage," International Journal of Hepatology, vol. 2011, Article ID 893973, 8 pages, 2011.
[9] J. Cheung, I. Soo, R. Bastiampillai, Q. Zhu, and M. Ma, "Urgent vs. non-urgent endoscopy in stable acute variceal bleeding," American Journal of Gastroenterology, vol. 104, no. 5, pp. 11251129, 2009.

[10] Y.-C. Hsu, C.-S. Chung, C.-H. Tseng et al., "Delayed endoscopy as a risk factor for in-hospital mortality in cirrhotic patients with acute variceal hemorrhage," Journal of Gastroenterology and Hepatology, vol. 24, no. 7, pp. 1294-1299, 2009.

[11] Y.-C. Hsu, C.-C. Chen, and H.-P. Wang, "Endoscopy timing in acute variceal hemorrhage: perhaps not the sooner the better, but delay not justified," American Journal of Gastroenterology, vol. 104, no. 10, pp. 2629-2630, 2009.

[12] Z. Luo, J. C. Gardiner, and C. J. Bradley, "Applying propensity score methods in medical research: pitfalls and prospects," Medical Care Research and Review, vol. 67, no. 5, pp. 528-554, 2010.

[13] J. D. Seeger, P. L. Williams, and A. M. Walker, "An application of propensity score matching using claims data," Pharmacoepidemiology and Drug Safety, vol. 14, no. 7, pp. 465-476, 2005.

[14] Y. K. Lee, C. C. Chen, H. Y. Lin, C. Y. Hsu, and Y. C. Su, "Propofol for sedation can shorten the duration of ED stay in joints reduction," The American Journal of Emergency Medicine, vol. 30, no. 8, pp. 1352-1356, 2012.

[15] F. Bendtsen, A. Krag, and S. Møller, "Treatment of acute variceal bleeding," Digestive and Liver Disease, vol. 40, no. 5, pp. 328-336, 2008.

[16] G. D’Amico, G. Pietrosi, I. Tarantino, and L. Pagliaro, "Emergency sclerotherapy versus vasoactive drugs for variceal bleeding in cirrhosis: a cochrane meta-analysis," Gastroenterology, vol. 124, no. 5, pp. 1277-1291, 2003.

[17] B. M. Yan and S. S. Lee, "Emergency management of bleeding esophageal varices: drugs, bands or sleep?" Canadian Journal of Gastroenterology, vol. 20, no. 3, pp. 165-170, 2006.

[18] G. Garcia-Tsao, A. J. Sanyal, N. D. Grace, and W. D. Carey, "Prevention and management of gastroesophageal varices and variceal hemorrhage in cirrhosis," The American Journal of Gastroenterology, vol. 102, no. 9, pp. 2086-2102, 2007. 


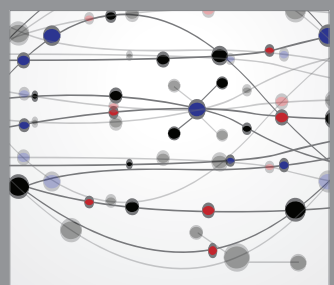

The Scientific World Journal
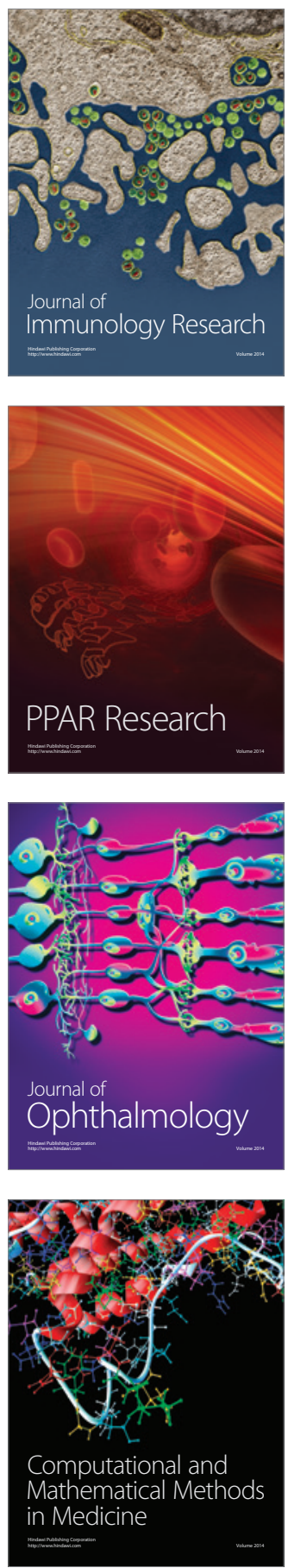

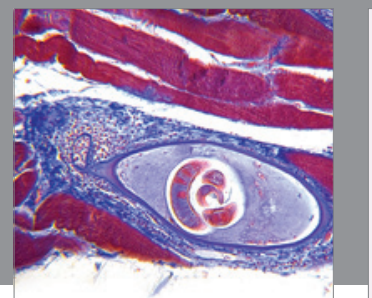

Gastroenterology

Research and Practice
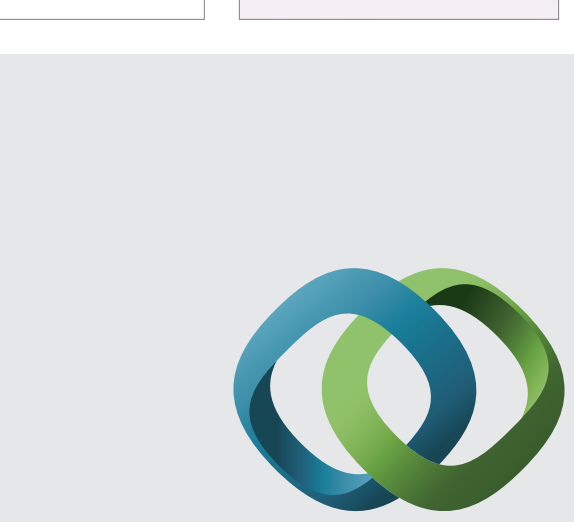

\section{Hindawi}

Submit your manuscripts at

http://www.hindawi.com
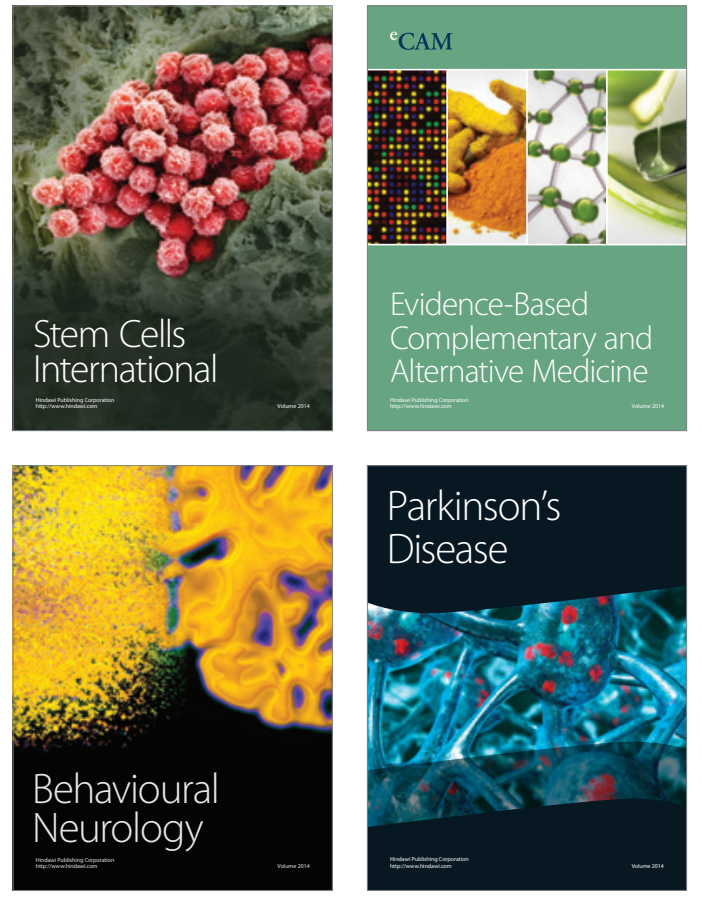
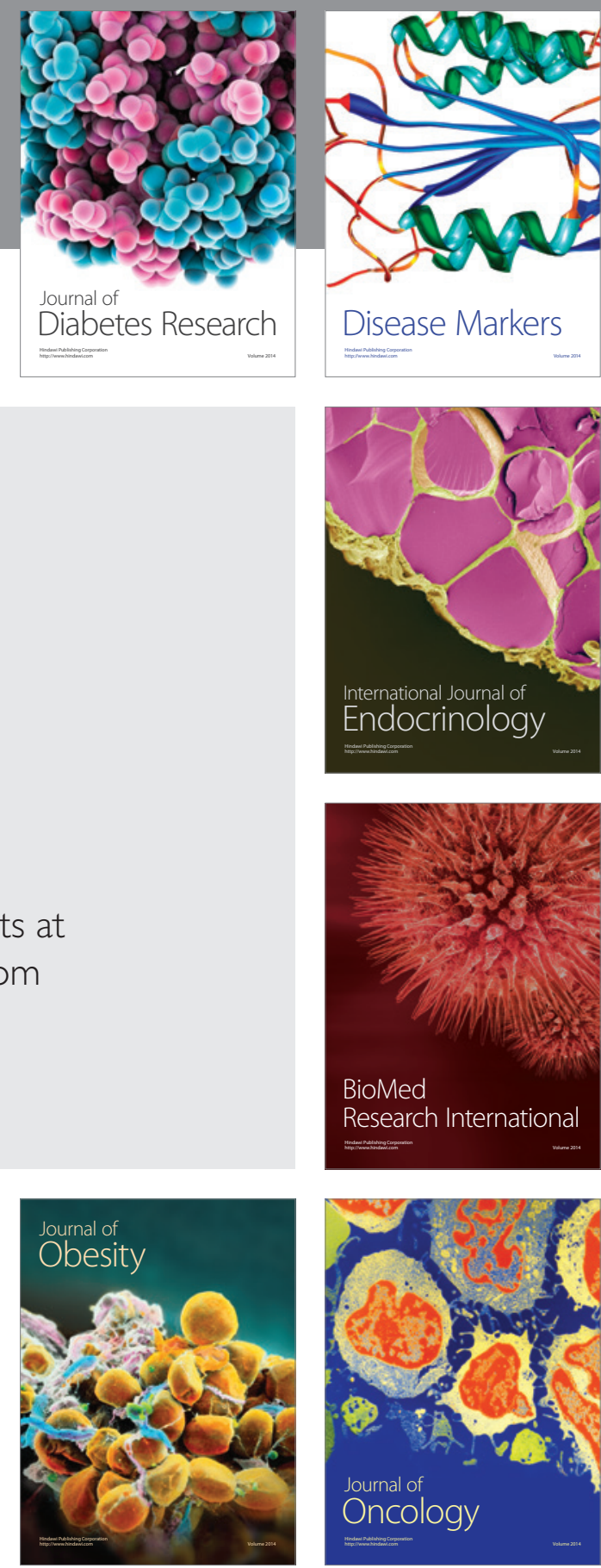

Disease Markers
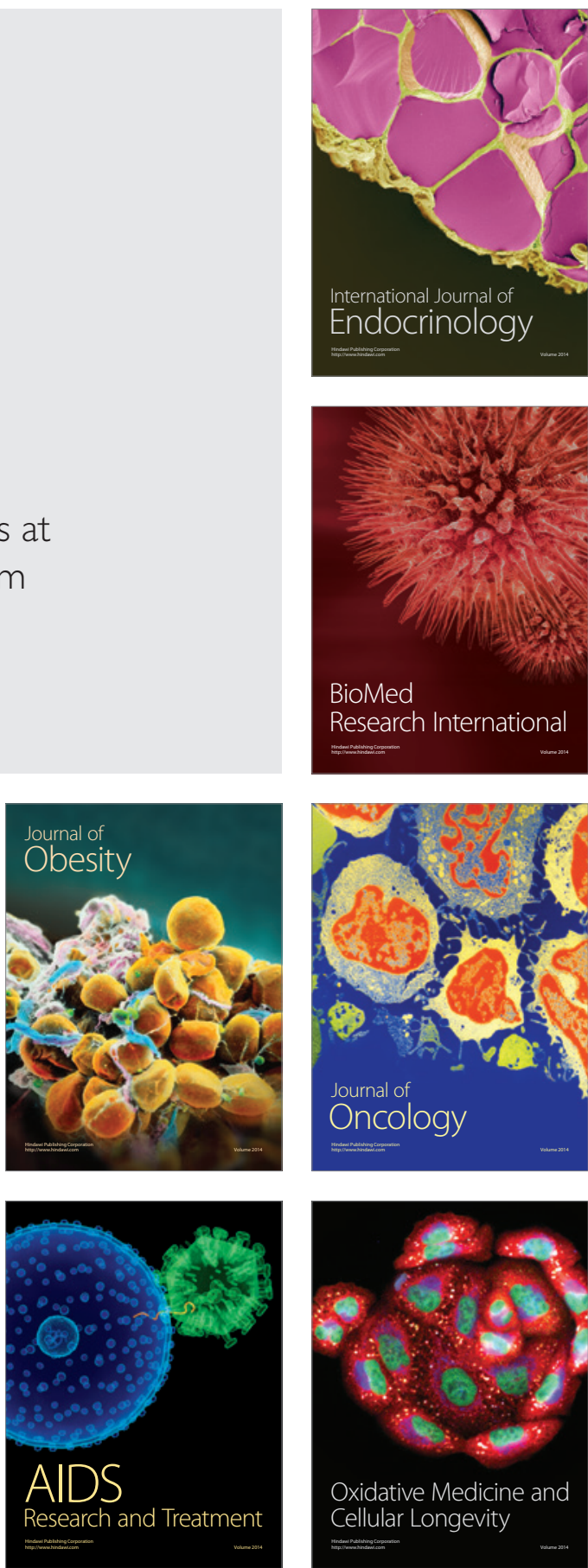